Article

\title{
Promoting Sustainable Development of Cultural Assets by Improving Users' Perception through Space Configuration; Case Study: The Industrial Heritage Site
}

\author{
Hassan Bazazzadeh ${ }^{1, *} \mathbb{0}$, Adam Nadolny ${ }^{1}$, Koorosh Attarian ${ }^{2}$, Behnaz Safar ali najar ${ }^{2} \mathbb{D}$ and \\ Seyedeh sara Hashemi safaei ${ }^{2}$ \\ 1 Division of History, Theory and Heritage, Faculty of Architecture, Poznan University of Technology, \\ 60-965 Poznan, Poland; Adam.nadolny@put.poznan.pl \\ 2 Faculty of Architecture, Jundi-Shapur University of Technology, Dezful 64616-18674, Iran; \\ attarian@jsu.ac.ir (K.A.); behnaz.najar@jsu.ac.ir (B.S.a.n.); Sarahashemii92@gmail.com (S.s.H.s.) \\ * Correspondence: Hassan.bazazzadeh@doctorate.put.poznan.pl; Tel.: +48-66275-1647
}

Received: 15 May 2020; Accepted: 19 June 2020; Published: 23 June 2020

\begin{abstract}
The role of the cultural assets as one of the pillars of sustainable development is undeniably of great significance in the cultural sustainability of cities. Indeed, the way users understand and interpret cultural heritage sites would be highly critical to managing cultural organizations properly. It means by improving users' perception of these sites, it can expect a fair distribution of comprehensive awareness among generations about the values of cultural assets. Past studies in spatial psychology have demonstrated that environmental properties can positively Influence human emotions. On the other hand, using computational-mathematical methods used to examine spatio-visual properties have rarely been compared to human perceptions. This paper examines the impact of spatio-visual properties on human perception as a clever cultural management strategy to promote cultural sustainability. It is discussed how environmental features in general, and visibility in particular, can shape the way users interpret cultural heritage. Results indicate that not only visibility of users' paths within cultural heritage sites can be an influential factor for the development of users' perception, but also the visibility of the entrance of these complexes can change their understanding. This means that decision-makers, architects, and managers of the cultural organizations can apply these findings as cultural management framework by defining predefined paths in these sites in the way that they possess high visibility and visible entrance. Consequently, the distribution of public awareness among generations can be improved to strengthen the role of cultural aspects in sustainable development.
\end{abstract}

Keywords: cultural sustainability; cultural management; industrial heritage; users' perception; visibility

\section{Introduction}

Culture, one of the foundations of sustainable development and co-creator of our future is considered as a factor that changes in natural areas and cultural landscapes are known as its results [1]. This aspect needs thorough studies to understand its supporting role in culture [2,3]. The concept of sustainability is connected to the adaptability of society by making a balance between needed development and values protection from various perspectives [4]. In the context of cultural heritage, the preservation of values should be considered in cultural management as it can lead to the sustainability of society. However, preserving cultural heritage values requires a diverse cultural 
management framework due to its potential divergent values [5]. Indeed, unlike other types of cultural objects, cultural heritage buildings and sites are needed to understand and recognized by generations to fulfill their support role in achieving sustainable development. Therefore, attracting people in these sites through some strategies like reuse is highly recommended by scholars and experts.

Proper reuse of these buildings demands a thorough study and assessment of their environment and the way it affects people. Since the people's understanding of these sites can be a smart cultural management strategy to promote cultural dimension as a pillar of sustainable development. This feature can form the psychological pulses from the environment to humans [6]. Various theories aim to provide an accurate insight into the built environments and its effects on the way people behave namely space syntax theory and Prospect refuge. These theories are frequently used to analyze people's behavior, especially in public spaces. Clinic of Freiburg University, Conference center of Lubick in Germany, Tate Gallery in London, and Baltic house neighborhood in London for instance are among many cases of implementing space syntax theory in practical attitude. These theories discuss the impact of the spatial configuration of a space, on the behavior of people. Examining users' perceptions of any space leads to measuring people's awareness of space and the structural purpose of space. In cultural heritage sites, this knowledge and awareness can improve the future sustainable development of them as economical and management aspect. Therefore, in this study, the users' perception of a site that is considered as the industrial heritage of Dezful city has been measured. Consequently, this research focus on the impact of one of the environmental properties of space -visibility- on users' perception of cultural heritage sites. This research aims to adopt a visibility analysis alongside with field research and questionnaire to analyze the emotional responses of users based on environmental psychology theories and spatial configuration theories. Accordingly, visibility analysis as an effective way to measure the perceptual responses is selected as the main variable of this research and an industrial heritage site in Dezful is selected as the case study of this research. This research focuses on neglected industrial heritage as a branch of cultural heritage [7-9] which benefits from a considerable spatial behavior in local and urban heritage, which could play a significant role in gaining tourist attraction and urban cultural management.

\section{Materials and Methods}

\subsection{Research Background}

Space syntax theory, one of the pioneer and popular research methods, seeks the role of spatial configuration on shaping peoples' behavior. A countless number of studies have been done using this method to research the relationship between the physical conditions of spaces and users' behavior through space configuration analysis. Studying the pedestrians' behavior in urban sites [10], the relations between forming factors, cognitive and users' behavior [11,12], ability to find a direction and its relation to forming factors of space [13], the relations between physical conditions and spatial experiences of people [14] are some of the researches in this area. Analyzing users' behavior in the form cognitive map initially was done by Hull who studied mice's movements for finding food in mazes [15]. Edward Chace Tolman was somehow the first person to mention the term "cognitive maps" in his research [16,17]. Cognitive maps processed information from the senses, are represented in human memory and provide data by which analysis could be meaningful [18]. According to Haq's theory, there are two methods for creating cognitive maps: one is through the direct relationship to the physical environment and the other is indirect representative through theological and oral media such as maps, static, and motion pictures [19]. Cognition of the features of the built environment has been a matter of debate amongst architects and designers for years and has led to the emergence of several theories and notions. One of them is space syntax, which studies the relationship between physical conditions in the form of space configuration variables and users' behavior theory. By Hillier and Hanson in 1984 in London, space syntax theory believes that space is the primary core and a principle in quality social and cultural events. Although space is formed around social, cultural, and economic 
processes, it is regularly considered as a substratum for social and cultural activities until its form is not considered and it is assumed as an invisible quality [20]. One of the items which are known as an effective element in this theory is visibility. Polygon of visibility in two or three-dimensional forms (Isovist) is a polygon that a person could observe based on the conditions and obstacles of the environment [21]. (See Figure 1) This variable defines that spaces that are excluded from the visibility polygon and are hidden from the user's direct vision do not affect user's behavior and their perception of space.

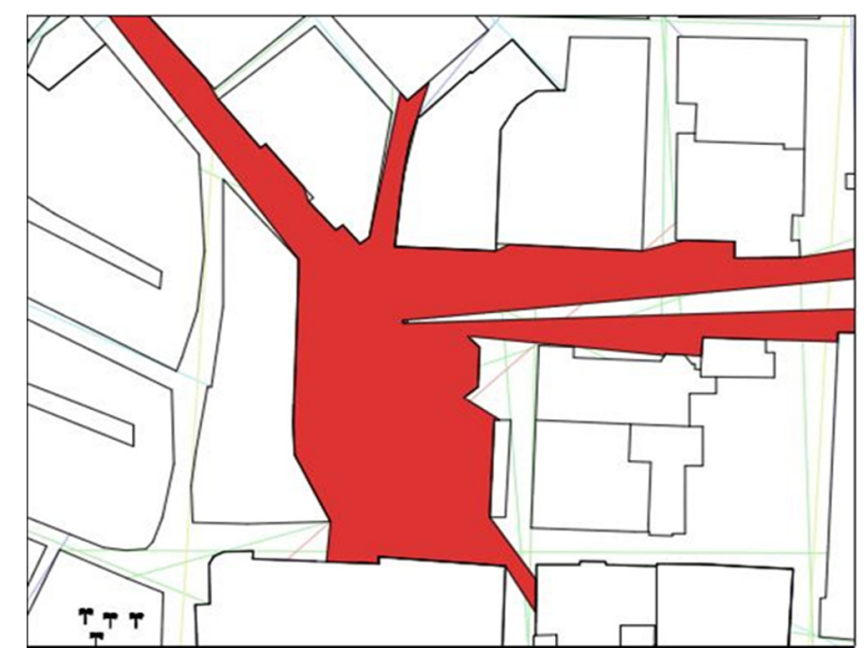

Figure 1. Visibility polygon of Biskra plaza [22].

Over the last few decades, a growing number of studies have tested the relevance of various theories derived from spatial psychology to design [23]. Research on the spatial characteristics of historical districts in the fields of architecture, landscape architecture, and urban design is largely qualitatively-based on environmental cognition information of tourists and users being derived using interviews, questionnaires, cognitive maps, and factor analysis. In recent years, the space syntax model has been widely used in the fields of architecture and urban planning [24,25]. In light of a large number of studies on the comparison and relationship between space syntax model and space image and cognitive map, Turner [26] believed that there was a relationship between isovist graphs and visibility graphs, which can be used in the study of spatial cognition. Tao [27] combined the axis map and image map to discuss the spatial forms of villages. Koohsari [28] took the historic block of Taiping Street in Changsha, Hunan Province as an example, comparing the cognitive map with the space syntax model, and found that the space syntax model had a high degree of correlation with the node and road network in the cognitive map. Some studies sought to test and revise the research conclusions of the space syntax model using experiments upon tourists' behaviors and analysis of their comments [24]. The theories that have been tested have typically identified various spatial properties-including openness, enclosure, mystery, and complexity-which have been linked to feelings of emotional well-being. While the results of these have ranged across the spectrum from positive to negative, they nevertheless signal serious interest in identifying and examining precise spatial and perceptual properties in architecture [23]. An isovist is 'the set of all points visible from a given vantage point in space'. Isovists change their shape and size depending on the chosen observation point within an environment, which allows them to reveal 'location-specific patterns of visibility' [29]. An isovist thus defines a field of vision from which various geometrical properties, such as area and perimeter, can be calculated. Isovists can be defined for every vantage point constituting an environment, and the spatial union of any particular geometrical property defines a particular isovist field [30]. Isovist analysis offers a method for comparing the mathematical properties of different views which can also be categorized in terms of distinct spatial qualities. Significantly, past research has selectively used 
isovist measures in the context of examining perceptual responses to space [23]. One way is to create, for objective examination, all the isovists that belong to a given path through a given environment. This in turn can be achieved in some ways. It is desired to describe in some detail a way of handling isovists that leads on from the quantification of isovist attributes presented earlier, and which continues the program of finding a field description for environments. It has already been remarked that the shape and size of an isovist are unique to an environment and a vantage point and are liable to change with observer movement. In this way, every environment creates 'isovist information fields' or isovist fields unique to it [29].

\subsection{Methodology}

The method adopted in this paper combines an empirical survey with a mathematical and computational approach (isovist analysis) to test the relationship between perceptual responses and actual properties of the intended space. It has been suggested frequently by various scholars (e.g., [31-33]) that the spatial layout of the built environment heavily influences the accuracy of cognitive representations of real-world spatial information [34]. Shaped by users' perception [35] through their visional aspects [36], a cognitive map is a great way to analyze the understanding of people. Despite the few criticisms about the reliability of this method, its function and employment through spatial cognitive studies show that this method is still beneficial and appropriated in eliciting the cognitive features of environments [37,38]. The aim of this paper falls within this area, which, indeed, is clarifying the impact of the Spatial properties on the way people perceive the environment. To assess the users' cognitive representations of the intended environment, the cognitive map is selected as an effective tool to measure how people perceive and recognize their built environments [39].

It should be noted that cognitive mapping is, in turn, a process of mental representation of the spatial knowledge [40], which contains individual acquires, stores, recalls, and decodes information about the relative locations and attributes of the phenomena in the intended environment [41]. There are three methods for the derivation of a cognitive map.

- questionnaire survey

- documentary coding

- interviews [42]

The first method employs a questionnaire that allows the aggregation of individual opinions based on a much wider range of information than documentary analysis. The questionnaire survey should be optimized by identifying potentially relevant variables and limiting the number of variables by rating their importance [43]. Consequently, route-type and survey-type subjects are selected as the most significant aspects of the cognitive map as the main themes of the questionnaire according to Steyver and Kooijman [44] (Appendix A).

In the present study, to determine the number of subjects, sightseers of the complex within working hours (9:00, 12:00, 16:00, 18:00) are observed and numbered. On the other hand, by using the Kukran formula and Morgan table and considering the error level to 5 percent, 30 subjects for each path are selected and 3 main paths observed. Therefore, 90 architecture students, 22-26 years old, voluntarily participated in the present study, after signing an informed consent document. They are the students of architectural engineering from two universities in Dezful. All the participants are Iranian and none of them from Dezful and the ratio of men to women is 1:1. The study is carried out under a permit from the Dezful's municipality. Each participant is tested individually, without interaction with others. All subjects were informed before testing that they are going to participate in a study on exploring the impact of spatio-visual properties of architectural space on users' perceptions. Testing began with a brief verbal description of the complex. This description is classified into a route-type description, a survey-type (overview) description, similar to the classification of the questions. The subjects were then led into the test area from the specific starting point and were asked to follow the predefined 
walking paths run through the complex for $10 \mathrm{~min}$. Then, the questionnaires were given to the subjects and they were requested to fill them out based on their previous experience in the complex.

On the one hand, the significance of the visual impact of the environment on the emotional response (like users' perception), has been frequently pointed out through various theories like Space syntax theory [17] and Prospect refuge theory [45]. On the other hand, the perceptual properties are usually tested using surveys, whereas almost all of the geometric studies use isovist analysis. This kind of analysis, meanwhile, is a powerful method for quantifying the physical environment [46] as Dosen and Ostwald [47] investigated the correlation between the human perception of simple space and isovist measures. While isovist analysis considers a small number of relatively independent isovists in an intended space, isovist field analysis is associated with specified paths through space $[48,49]$. Consequently, to reach the goal of this study examining all the isovists that belong to a given path through a given environment is needed and that is why the isovist field is applied. Since this paper is only concerned about the relationship between human perceptions and the spatio-visual properties through the visibility, the extent of isovist analysis is limited to its correlation with human perceptions. Another significant aspect of this research according to hypotheses is the isovists of entrances that are also calculated for each path. Finally, the data derived from isovist analysis and questionnaire are then exported to SPSS software for further analyses, then compared, and the results of this comparison are interpreted.

\subsection{Research Scope and Case Study}

In this research, the psychological evaluation of users' is examined and more precisely, the visual feature in the user's perception has been done in a building that has been used as an industrial heritage in the city of Dezful and now has changed. According to the official description, industrial heritage includes remained examples of industrial culture which enjoy historic, technological, architectural, and scientific values $[50,51]$. Due to the structural changes, and effective elements such as social and economic conditions, industrial spaces regularly change to respond to new conditions. These elements represent culture, historic positions, technology, processes, and distinct achievements of the area [52]. Knowing the merits of industrial heritage can improve its management and could be in the form of industrial tourism, conferences, exhibitions [53]. Values of industrial heritage could be divided into these categories:

- Historic value

- Technologic value

- Economic value

- Educational value

- Psychological value [54]

To have a comprehensive knowledge of industrial heritage must be accurately described and classified (See Figure 2) for possible future legal challenges [55].

Recognition of industrial heritage is not limited to theoretical subjects, it, in turn, can shape users' behavior as it includes shared memories added to the built environments [14]. Hence, the users' perception of industrial heritage could eventually lead to appropriate management and proper measures. As a new branch of cultural heritage, industrial heritage sites mainly have a relatively special situation. 


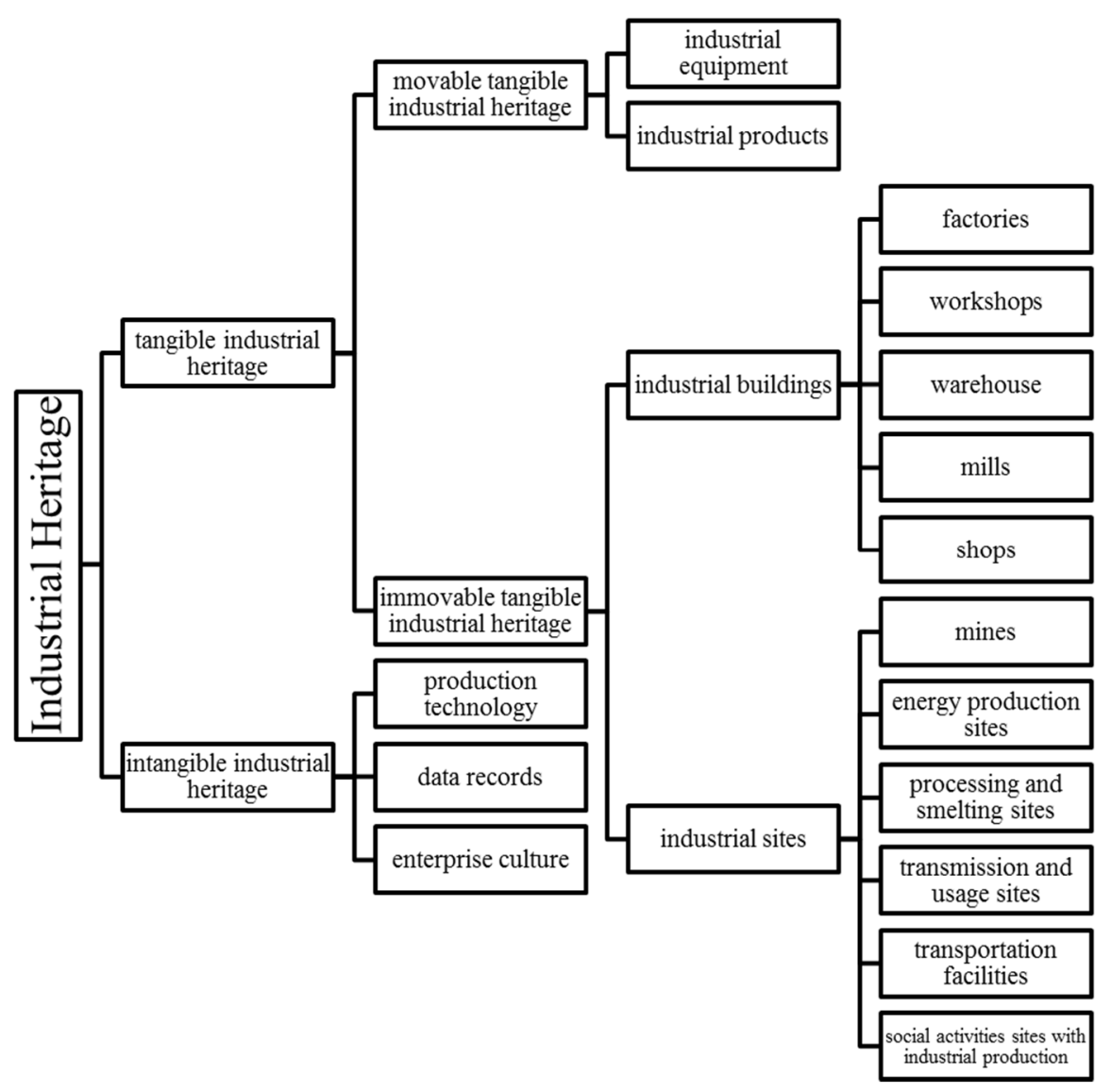

Figure 2. Industrial heritage classification [56].

At the Qajar dynasty (1795-1925) because of the urgent need for military technology and the establishment of modern schools in Iran, the process of industrialization in Iran significantly developed, and transport infrastructures, more than 270 factories, government buildings, and national railroad were among the most critical ones. This phenomenon caused the formation of a new civil society and created notable changes in the method and process of the human life of this era through industrial structures and buildings. Therefore, almost all industrial sites and buildings of the Qajar and Pahlavi era as signs of the dominant industrial culture and the evidence of the industrialization process in Iran are known as the industrial heritage of Iran. Among different cities in Iran Dezful has an interesting story during industrialization, which makes it a great example of industrial impacts on a city, which leads to changing the image of the city. Dezful, one of the biggest cities in the Khuzestan province in the south of Iran, has been a center of governors' attention for its climate and agricultural potentials since Qajar and the central government of Iran times $[57,58]$. It also had been known for its agricultural products before the industrialization process in Iran. This industry was completely traditional due to the lack of required knowledge, investment, machinery, and proper marketing. It was the time when other countries entered this region to create businesses and financial investments, hence to create jobs workshops and ranches and houses for settlement were established. These activities changed the image of the city from an agriculture city to an industrial one and made industrial culture, popular amongst the natives. As a consequence, the establishment of industrial workshops became common in Dezful. According to general definition and categorization in previous parts, industrial heritage sites of Dezful could be named as Flour workshops (Makineh Aardi), Ice workshops (Makineh Yakhi), Electricity workshops (Makine Barqi), Brick furnaces, The Old water supply, Concrete bridge of Dezful (Pol-e-Jadid or the new bridge), Facilities and settlement of Sevvom Sha'ban (English architecture) and other small buildings. Among all of these industrial heritage sites, Flour workshops (Makineh Aardi) had the strongest connection with the society, as the users of these sites, instead of industry owners 
and professionals, were ordinary people who came there to grind wheat regularly. As a result, the role of these sites in the historical memory of the people of Dezful is stronger than any other industrial site. The location of the DastPacheh flour workshop (Makine Aardi Dastpacheh) beside the historical fabric of Dezful at the Eastern Sahrabedar quarter caused the place a historic settlement before the industrial age. (See Figures 3 and 4). This heritage inferred from tangible heritage, immovable heritage, industrial buildings, and workshops [55]. This place has turned into a fruit and vegetable market these days and is a subsidiary branch of a bazaar called Bazar-e-ruz (Day bazaar) amongst natives.

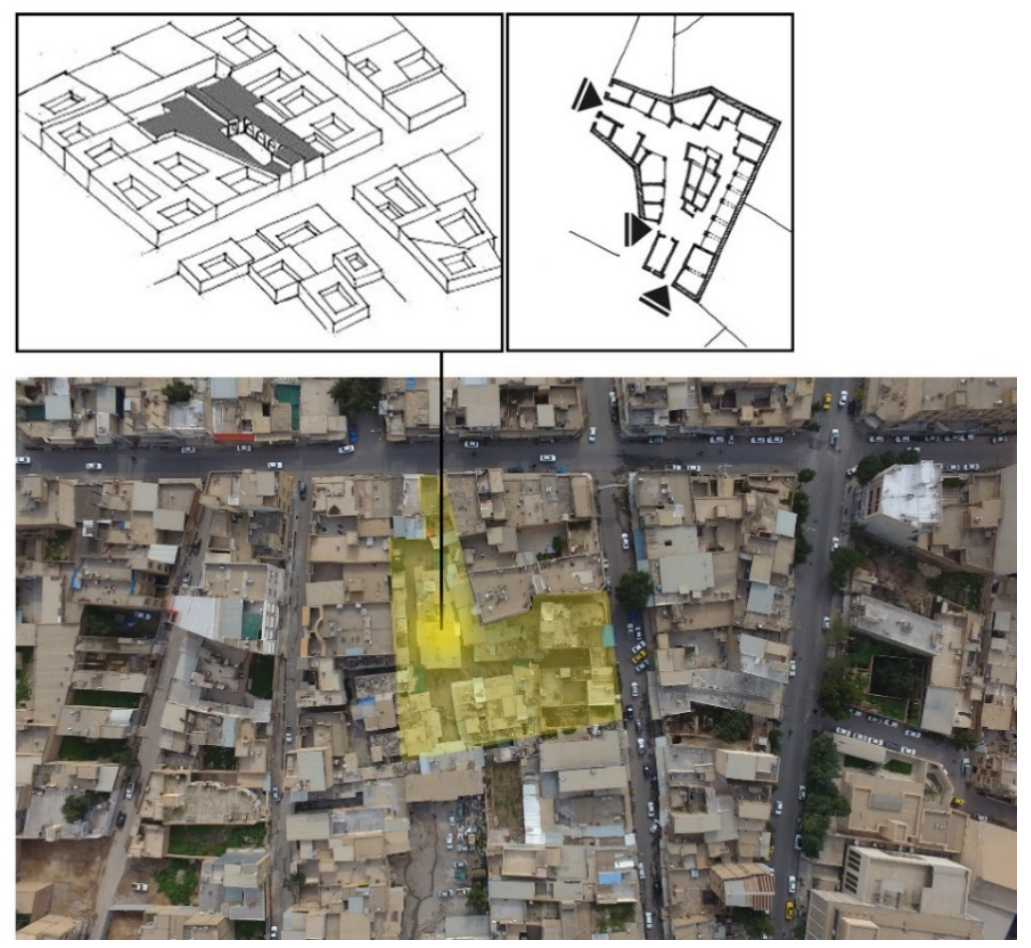

Figure 3. The location of Makine Aardi Dastpacheh beside the historical fabric of Dezful.

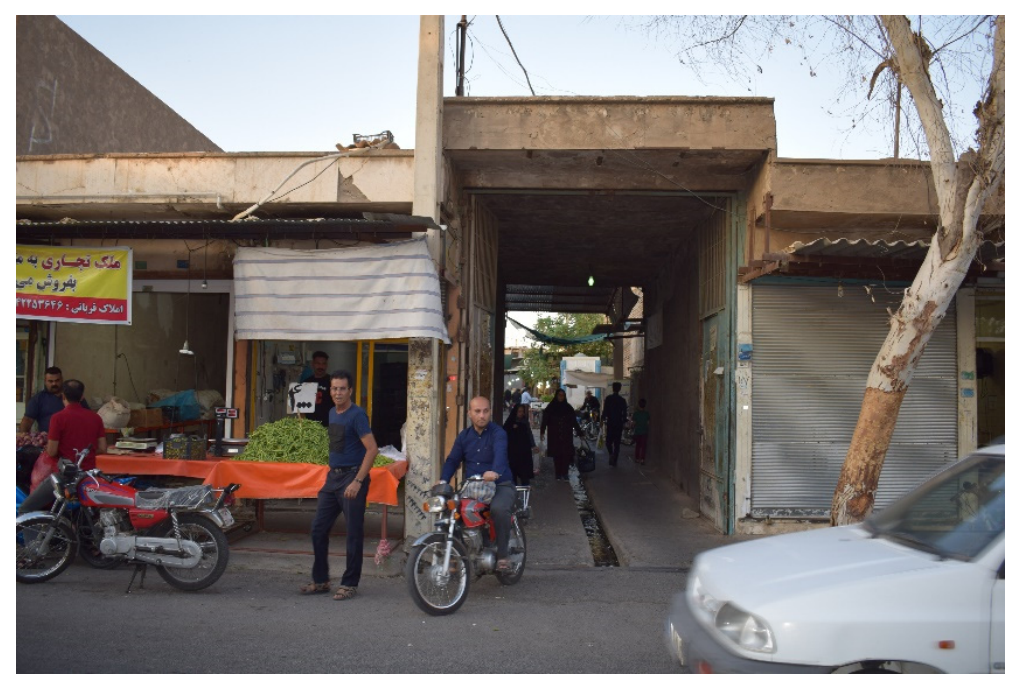

Figure 4. Main entrance of "Makine Aardi Dastpacheh".

This Makineh (Workshop) was one of the largest flour Makinehs in the city aside Makineh Kaj-Baf known as Makineh Aardi Dastpacheh. It is the most important flour workshop in Dezful not only for its functional aspect (it met the needs of wheat grinding for a large part of the city) but also for its location (it was once located at the edge of city's borders and now is located at the edge of historic 
core in the heart of the city). Despite having an unforgettable role in the historical memory of natives, Makine Aardi Dastpacheh is vulnerable because of different issues. Firstly, spontaneous reuse has been applied here by locals, which has turned this flour workshop into a fruits and vegetable market. Secondly, it is located in the heart of the city now, where the land value is quite high, and the city's authorities have a strong desire to destroy this site and turn it into a high-rise mixed-use complex. In this situation, it is extremely critical to apply some cultural management strategies to enhance people's awareness about this site and attract more users to this cultural heritage site to regain its significant role in the city as a cultural heritage and an inseparable part of the collective identity and memory of the people.

\section{Results}

To reach the research goal and studying the between spatio-visual properties in general, and visibility in particular, and user perception, as the first stage architectural drawings are made. Drawings are imported into UCL Depth Map [59] and Isovist app to analyze the isovist field for major paths (see Figure 5). That has been derived from field observations. Although the form of the second and the third route is the same the direction is quite different, and this similarity helps the research to go one step deeper.
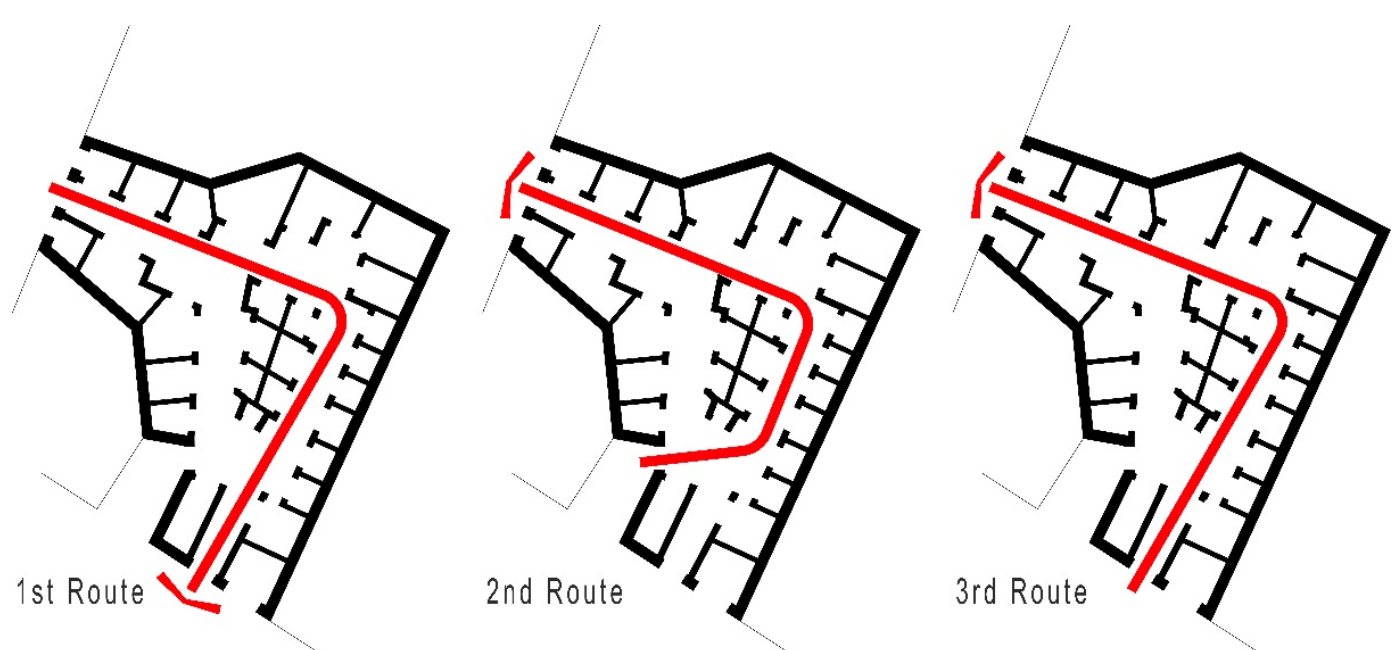

Figure 5. Surveyed route from different entrances of "Makine Aardi Dastpacheh".

The results of isovist field analysis of each path, alongside with the isovist analysis of the starting point of each path (See Figure 6) is demonstrated in Table 1. The visibility of entrance is the only variable which differentiates the results for the second and the third path.

On the other hand, the results of the questionnaires are summarized in Table 2, where the rate of accuracy of each interviewee based on the reality is assessed. To have promising reliability for questionnaires, the method of inner consistency Cronbach's alpha coefficient is used. The inner consistency method emphasizes the consistency or the monotony of components of the test. As the test is held once with a group of examinees or a pre-test is held. If the amount of Cronbach's alpha was bigger than 0.7, the test is reliable. By measuring the Cronbach's alpha (0.884) and since it is bigger than 0.7 , the test meets the needs of reliability. 

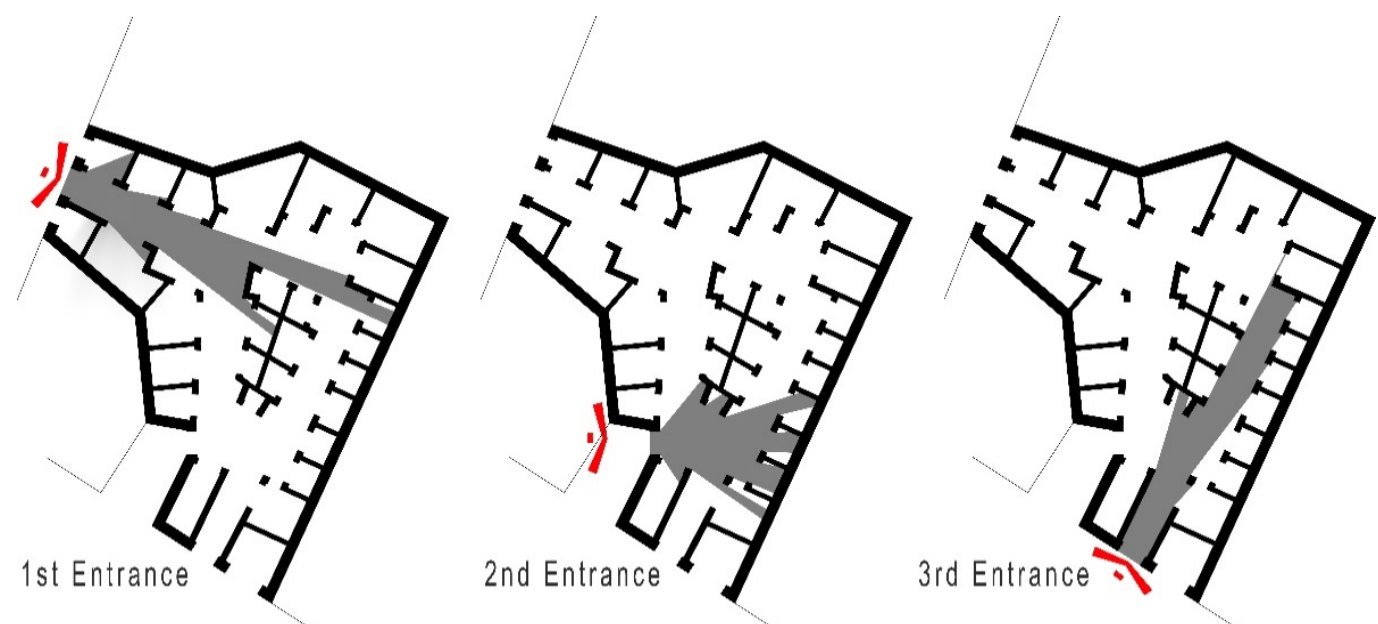

Figure 6. Visibility polygons of different entrances of "Makine Aardi Dastpacheh".

Table 1. Results of visibility for each path.

\begin{tabular}{cccc}
\hline Route & Length of Route $(\mathbf{m})$ & Isovist Field & Entrance Visibility \\
\hline First & 68 & 105.73 & 93.42 \\
Second & 55 & 89.52 & 62.76 \\
Third & 68 & 105.73 & 73.65 \\
\hline
\end{tabular}

Table 2. Results of the questionnaire.

\begin{tabular}{ccccccc}
\hline Route & $\begin{array}{c}\text { Length of Route } \\
(\mathbf{m})\end{array}$ & $\begin{array}{c}\text { No. of } \\
\text { Interviewee }\end{array}$ & Maximum & Minimum & STDEV & Average \\
\hline First & 68 & 30 & 83.63 & 48.5 & 15.32 & 71.4 \\
Second & 55 & 30 & 61.83 & 27.42 & 38.72 & 41.52 \\
Third & 68 & 30 & 86.28 & 43.73 & 21.63 & 62.25 \\
\hline
\end{tabular}

\section{Discussion}

We used UCL Depthmap and Isovist app [59] to perform isovist analysis. This software provides three types of visibility analysis, specifically isovist analysis, isovist field analysis, and VGA. The isovist analysis is appropriate for predefining observation points, while the isovist field provides the visibility polygon for the whole path. On the other hand, VGA is suitable for providing an encompassing overview of the visibility distribution of the complex. Indeed, the selected variables show the potential of a specific point, path, and the entire complex respectively in terms of visibility. By reviewing the result of these experiment some facts should be pointed out. Firstly, it is clear that the more a path crosses points with high visibility the higher average visibility it has which seems an obvious conclusion (see Figure 7).

Secondly, by taking a brief look at Table 2, it is expected that the perception of users who explore the complex through the first and the third path undoubtedly should be higher as these routes are longer than the second one. While this conclusion is quite true, yet it is not the only logical explanation. If the length of the path was the only influential factor in determining, the rate of understanding of users, the differentiation between the first and the third path could not be justified. Therefore, the role of the isovist field cannot be ignored. Within the comparison analysis (see Table 3), this research goes deeper to study the relationship among users' perceptions and visibility. The notable result of this phase apart from the relationship between the isovist field of each path and users' perception, is the fact that visibility at the entrance plays a vital role. Although the first interpretation of the isovist field is not very surprising, yet the second one seems strange at first glance. This means that apart from the 
features of the path in general, the condition of the entrance can differentiate the users' perception about cultural heritage sites, as it is the only variable, which tends to be different between the first and the third path. Taking this result into account, it can be concluded that the more visible entrance a path in cultural heritage site has, the better perception of users can be expected.

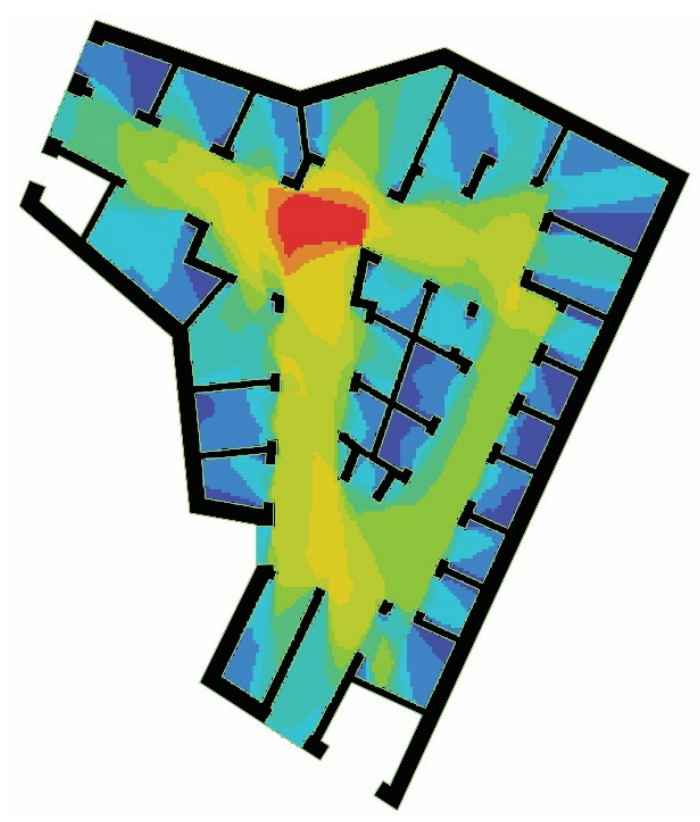

Figure 7. VGA of the entire complex.

Table 3. Summary of comparative analysis.

\begin{tabular}{ccccc}
\hline & Examined Factors & V1 & V2 & V3 \\
\hline \multirow{4}{*}{ V1 } & Users' perception & 1 & 0.716 & 0.838 \\
& Sig. (2-tailed) & - & 0.015 & 0.006 \\
& N & 90 & 90 & 90 \\
\hline \multirow{4}{*}{ V2 } & Average Visibility & 0.716 & 1 & 0.582 \\
& Sig. (2-tailed) & 0.015 & - & 0.035 \\
& N & 90 & 90 & 90 \\
\hline \multirow{2}{*}{ V3 } & Visibility of entrance & 0.038 & 0.582 & 1 \\
& Sig. (2-tailed) & 0.006 & 0.035 & - \\
& $N$ & 90 & 90 & 90 \\
\hline
\end{tabular}

According to Table 3, a strong positive correlation between users' perception and visibility of paths (0.716) can be observed. An interesting result of the comparison phase is the stronger positive correlation between users' perception and the visibility of the entrance of each path. It means that while the visibility of the entire path is very significant in shaping users' perceptual responses, the impact of the visibility of the entrance is far more important in forming users' perception.

\section{Conclusions}

Concerning cultural sustainability as one of the substantial pillars of sustainable development, the importance of cultural assets cannot be ignored. Cultural heritage sites as one of the significant phenomena of this dimension are regarded as active players in the sustainability of cities. While industrial heritage sites have this potential to be critical grids of cities, they are under serious threats due to their special feature which makes them too unique to classified as cultural heritage at first glance. Indeed, these sites as an inseparable part of the collective identity and memory of each society need proper cultural management strategies to invite people such as adaptive reuse practice. 
However, attracting people to these sites is not limited to adding an adaptive function through adaptive reuse practice, but raising public awareness about their values. Therefore, the cultural management strategies to strengthen cultural sustainability through enhancing users' perception in these sites has turned into a critical urban subject. Since the psychological aspect of the experience of cultural heritage has proven to drastically revolutionize people's thoughts towards these sites, by improving this aspect we could widen people's horizons about the importance of cultural heritage sites. On the other hand, within the increasing interest in environmental psychology theories in architecture, the assessment of spatial properties mathematically or computationally seems an on-board topic since findings of these researches can be adopted in architectural practices (like cultural heritage sites) as cultural management framework to improve the positive psychological impacts and subsequently to reach cultural sustainability. While this area is highly significant in the quality users' experience, the computational-mathematical methods to examine spatio-visual properties have rarely been compared to human perceptions. As there is not ample evidence that users' perception correlates to isovist-based properties of space, this paper aims to present results of a study involving 90 participants, and their experience in the intended cultural heritage site is assessed. As we sought to clarify the impact of spatio-visual properties of cultural heritage on the quality of users' experience and the way to improve it, we investigated the correlative effects between the visual geometric attributes of industrial heritage sites of Dezful in Iran and its users' perceptions as a case study. This study has been conducted through combining the field trip method alongside with cognitive map method in the form of a questionnaire, and computational aids to calculate isovist analysis.

The results presented in this paper indicate a very high, positive correlation of users' perception with the visibility of the path through the intended space. Another higher positive correlation discovered is between the visibility of the starting point of the path-entrance-with users' perception. Overall, this confirms that human perceptions of relative environmental conditions, heavily depend on the visibility of the chosen path. The study also shows that visibility of the starting point of the chosen path can genuinely expand users' capacity for having a better perception of the environment. These results broadly support the idea that the physical aspect of the built environment is not the only determining factor that should be assessed to seek a better experience, but the psychological aspect through various ways also shapes perceptions. More specifically, the comparison of visibility analysis indicates that isovist measurement is a suitable variable to assess by which human perceptions can be analyzed. The isovist measures that have been derived from the starting points of each path do show a stronger positive correlation with the perceptual responses than the isovists filed of the entire paths. To conclude, the combined method used in the present paper-assessing visibility features of each path and testing people's perceptual responses in each path — proves to be a valuable approach to learn more about the relationship between the psychological and physical aspects of the space. However, there are limits to the present research that must also be taken into account for interpreting the results. For instance, although elements of tested paths have some negligible differences, they are considered the same to eliminate their potential effects on users' perceptions. These elements include color, style, texture, exposed structure, and the number of shops. Another limitation of the present study is the information about participants' backgrounds (where they grew up or lived for a long time) which may have a larger impact on human perceptions than architectural features. Nevertheless, the number of influential factors to influence human perceptual responses of architectural spaces are various and this issue can be studied through various disciplines. This research provides an insight into the architectural aspect of this perception and the role of spatio-visual properties of paths in cultural heritage sites. Future works could examine other aspects of this perception and eventually, a framework could be produced to guide the cultural management to promote sustainable development in this way. This means that by having more visible paths and giving sightseers a more comprehensive overview at the first moments of their experience in these sites at the entrance, their perceptions, and insight of these cultural assets could be improved. Such findings can inform researchers, managers of the cultural sector, and architects about the impact of visibility of paths in cultural heritage sites and the 
visibility of entrances in such places, and more importantly provide managers of cultural organizations with clever cultural management strategies to promote cultural sustainability as a foundation to reach sustainable development.

Author Contributions: Conceptualization, H.B.; Formal analysis, H.B.; Funding acquisition, A.N.; Investigation, H.B., B.S.a.n. and S.s.H.s.; Methodology, H.B.; Project administration, A.N.; Resources, H.B. and B.S.a.n.; Software, H.B. and S.s.H.s.; Supervision, A.N. and K.A.; Validation, H.B.; Visualization, S.s.H.s.; Writing-original draft, H.B. and B.S.a.n.; Writing-review \& editing, H.B., K.A. and B.S.a.n. All authors have read and agreed to the published version of the manuscript.

Funding: This research has received funding within the framework of the research project entitled "Mapping of architectural space, the history, theory, practice, contemporaneity" of the Faculty of Architecture, Poznan University of Technology.

Conflicts of Interest: The authors declare no conflict of interest.

\section{Appendix A}

\section{Description:}

\section{Questionnaire form}

This Questionnaire is carrying out as a part of research entitled "Promoting sustainable development of cultural assets by the enhancement of users' perception through space configuration" in Dezful. This research is under the permission of Dezful's municipality.

\section{Procedure:}

The test begins with a brief verbal description of the complex. This description is classified into a route-type description, a survey-type (overview) description, similar to the classification of the questions. You will be then led to the test area. We highly encourage you to follow the guide through the predefined walking paths run through the complex for $10 \mathrm{~min}$. Finally, you will be asked to fill the questionnaire out based on your previous experience in the complex.

\section{Personal information:}

Name and Surname: $\quad$ Year of Birth:

Gender: $\quad$ Highest Education:

Place of Birth: $\quad$ Previous experience of this place:

\section{Route-type questions:}

1. The starting point of the route is at the .... End of the complex
(a) Southern
(b) Western
(c) Southwestern
(d) Can't remember

2. After going through the gate, the first thing on your left is ... .
(a) A grocery store
(b) A fruit shop
(c) A vegetable shop
(d) Can't remember

3. Just after entering the complex, there saw a relatively large empty space ... . of you
(a) Left-hand side
(b) In front
(c) Right sand side
(d) Can't remember

4. Then, did you see two route-options? If so, which one did you choose?
(a) Yes, the left one
(b) Yes, the right one
(c) No, I didn't see
(d) Can't remember

5 . Did you turn to reach the corridor? If so, in which orientation?
(a) Yes, left
(b) Yes, right
(c) No, I didn't turn
(d) Can't remember

6. In the corridor, what kind of shops did you see in the first shops?
(a) A grocery store
(b) A fruit shop
(c) A vegetable shop
(d) Can't remember

7. When did you see the large supermarket chain?
(a) near the entrance
(b) after the corridor
(c) before the corridor
(d) Can't remember 
8. Where did you see the sewing shop?
(a) at the entrance
(b) at the end of the route
(c) at the left-hand side
of the entrance
(d) Can't remember

9. How many turns did you make in your path?
(a) 0
(b) 1
(c) 2
(d) Can't remember

10. The starting point of the route is at the ... . End of the complex
(a) Southern
(b) Western
(c) Southwestern
(d) Can't remember

\section{Survey-type questions:}

11. The shape of the complex is ...
(a) Rectangular
(b) Parallelogram
(c) curve shape
(d) Compound shape

12. How many main areas are in this complex
(a) 4
(b) 5
(c) 6
(d) Can't remember

13. Where is the facilities area?
(a) North region
(b) south region
(c) East region
(d) West region

14. How many types of shops do you see in the complex?
(a) 4
(b) 5
(c) 6
(d) 7

15. How many entrances this complex have?
(a) 2
(b) 3
(c) 4
(d) Can't remember

16. How many empty spaces the complex have?
(a) 1
(b) 2
(c) 3
(d) West region

17. Where is the location of the supermarket chain?
(a) North region
(b) south region
(c) East region
(d) West region

18. Where is the location of the sewing shop?

(a) Middle of the complex

(b) Southern region

(c) Western region

(d) Can't remember

19. What is the orientation of the corridor?
(a) South-North
(b) West-East
(c) Southwestern-
Northeastern
(d) Can't remember

20. What is the function of the middle part?
(a) Shops
(b) Facilities
(c) Empty spaces
(d) Can't remember

\section{References}

1. Chen, C. Study of the Hydraulic Landscape in Taoyuan Tableland: The Past, Present and Future. In Proceedings of the XVth International Congress of the International Committee for the Conservation of the Industrial Heritage, Taipei, Taiwan, 4-8 November 2012.

2. King, T.F. The Archaeological Survey: Methods and Uses; Heritage Conservation and Recreation Service; U.S. Department of the Interior: Washington, DC, USA, 1978.

3. Garagnanai, G.; Manferdini, A.M. Parametric accuracy: Building information modeling process applied to the cultural heritage preservation. In 3D-ARCH 2013; ISPRS: Trento, Italy, 2013; pp. 87-92.

4. Nocca, F. The Role of Cultural Heritage in Sustainable Development: Multidimensional Indicators as Decision-Making Tool. Sustainability 2017, 9, 1882. [CrossRef]

5. Avrami, E.; Mason, R.; De la Torre, M. Values and Heritage Conservation; Research Report; Getty Conservation Institute: Los Angeles, CA, USA, 2000.

6. Porteous, J.D. Environment and Behavior: Planning and Everyday Urban Life Reading; Addison-Wesley: Boston, MA, USA, 1977.

7. Duet, J. Industrial Heritage Retooled: The TICCIH Guide to Industrial Heritage Conservation; Routledge: Lancaster, UK, 2012. 
8. TICCIH. Taipei Declaration for Asian Industrial Heritage; TICCIH Press: Taipei, Taiwan, 2012.

9. Van Oers, R. Identification and Documentation of Modern Heritage; UNESCO World Heritage Centre: Paris, France, 2003.

10. Chang, D.; Penn, A. Integrated multi-level circulation in dense urban areas: The effect of multiple interacting constraints on the use of complex urban areas. Environ. Plan. B Plan. Des. 1998, 25, 507-538. [CrossRef]

11. Lay, M.; Reis, A.; Dreux, V.; Becker, D.; Ambrosini, V. Spatial Configuration, Spatial Behavior and Spatial Cognition: Syntactic and Perceptual Analysis of the Market Station Area in Porto Alegre. In Proceedings of the EDRA 36, Vancouver, BC, Canada, 27 April-1 May 2005.

12. Kim, Y.O. Spatial Configuration, Spatial Cognition and Spatial Behavior: The Role of Architectural Intelligibility in Shaping Spatial Experience, Bartlett School of Architecture, Building. Ph. D. Thesis, Environmental Design and Planning. University of London, London, UK, 1999.

13. Abdelbaseer, A.M. Evaluating way-finding ability within urban environment. In Proceedings of the 8th International Space Syntax symposium, Santiago, Chile, 3-6 January 2012.

14. Meilinger, T.; Franz, G.; Heinrich, H.B. From Isovist via Mental Representations to Behavior: First Steps Toward Closing the Causal Chain. Environ. Plan. B Plan. Des. 2012, 39, 48-62. [CrossRef]

15. Hull, C.L. Principles of Behavior: An Introduction to Behavior Theory; Oxford publication: Oxford, UK, 1943.

16. Tolman, E.C. Cognitive maps in rats and men. Psychol. Rev. 1948, 55, 189-208. [CrossRef] [PubMed]

17. Hergenhahn, B.R.; Olson, M.H. An. Introduction to Theories of Learning; Pearson Prentice Hall: Upper Saddle River, NJ, USA, 2005.

18. Bechtel, R.B.; Churchman, A. Handbook of Environmental Psychology; John Wiley \& Sons Publisher: New York, NY, USA, 2002.

19. Haq, S.U. Complex architectural setting: An investigation of spatial and cognitive variables through way finding behavior. Ph. D. Thesis, Georgia Institute of Technology, Atlanta, GA, USA, 2001. Unpublished.

20. Makrí, M.; Folkesson, C. Accessibility measures for analyzes of land use and traveling with geographical information systems. In Proceedings of 2nd KFB-Research Conference, Lund, Sweden, 7-8 June 1999.

21. Yohan, M.; Hwiyeol, J.; Jongin, K.; Jongin, R. Exploring Gender Differences in Spatial Orientation Ability on Representing Cognitive Map. Int. J. Psychol. Behav. Sci. 2016, 6, 91-98.

22. Bada, Y.; Farhi, A. Experiencing urban spaces: Isovists properties and spatial use of plazas. Courr. Du Savoir 2009, 9, 101-112.

23. Dosen, A.S.; Ostwald, M.J. Lived space and geometric space: Comparing people's perceptions of spatial enclosure and exposure with metric room properties and isovist measures. Archit. Sci. Rev. 2017, 60, 62-77. [CrossRef]

24. Xu, Y.; Rollo, J.; Jones, D.S.; Esteban, Y.; Tong, H.; Mu, Q. Towards Sustainable Heritage Tourism: A Space Syntax-Based Analysis Method to Improve Tourists' Spatial Cognition in Chinese Historic Districts. Buildings 2020, 10, 29. [CrossRef]

25. Turner, A. From axial to road-centre lines: A new representation for space syntax and a new model of route choice for transport network analysis. Environ. Plan. B Plan. Des. 2007, 34, 539-555. [CrossRef]

26. Turner, A.; Doxa, M.; O'sullivan, D.; Penn, A. From isovists to visibility graphs: A methodology for the analysis of architectural space. Environ. Plan. B Plan. Des. 2001, 28, 103-121. [CrossRef]

27. Tao, Y. Digital City and Space Syntax: A Digital Planning Approach. Planners 2012, 28, $24-29$.

28. Koohsari, M.J.; Sugiyama, T.; Mavoa, S.; Villanueva, K.; Badland, H.; Giles-Corti, B.; Owen, N. Street network measures and adults' walking for transport: Application of space syntax. Health Place 2016, 38, 89-95. [CrossRef] [PubMed]

29. Benedikt, M.L. To Take Hold of Space: Isovists and Isovist View Fields. Environ. Plan. B Plan. Des. 1979, 6, 47-65. [CrossRef]

30. Batty, M. Exploring isovist fields: Space and shape in architectural and urban morphology. Environ. Plan. $B$ Plan. Des. 2001, 28, 123-150. [CrossRef]

31. Appleyard, D. Styles and methods of structuring a city. Environ. Behav. 1970, 2, 100-124. [CrossRef]

32. O'Neill, M.J. Effects of signage and floor plan configuration on wayfinding accuracy. Environ. Behav. 1991, 23, 553-574. [CrossRef]

33. Walker, J. Representing Social Space: Cognitive Mapping and the Potential for Progressive Urban Planning \& Design. Trial Six Undergrad. Geogr. J. 2011, 5, 41-43. 
34. Papadopoulos, K.; Barouti, M.; Koustriava, E. Cognitive maps of individuals with blindness for familiar and unfamiliar spaces: Construction through audio-tactile maps and walked experience. Comput. Hum. Behav. 2017, 75, 376-384. [CrossRef]

35. Lang, J. Creating Architectural Theory: The Role of the Behavioral Sciences in Environmental Design; Van Nostrand Reinhold Publisher: New York, NY, USA, 1987.

36. Dalton, R.C.; Bafna, S. the Syntactical Image of the City: A Reciprocal Definition of spatial elements and spatial syntaxes. In Proceedings of the 4th International Space Syntax Symposium, London, UK, 17-19 June 2003.

37. Blaut, J.M.; Stea, D. Mapping at the age of three. J. Geogr. 1974, 73, 5-9. [CrossRef]

38. Golledge, R.G. Methods and methodologies issues in environmental cognition research. In Environmental Knowing; Moore, G.T., Golledge, R.G., Eds.; Dowden, Hutchinson and Ross: Stroudsburg, PA, USA, 1976.

39. Kim, Y.O.; Penn, A. Linking the spatial syntax of cognitive maps to the spatial syntax of the environment. Environ. Behav. 2004, 36, 483-504. [CrossRef]

40. Kitchin, R.M. Cognitive maps: What are they and why study them? J. Environ. Psychol. 1994, 14, 1-19. [CrossRef]

41. Downs, M.R.; Stea, D. Image and Environment: Cognitive Mapping and Spatial Behavior; Edward Arnold: London, UK, 1973.

42. Hwang, C.L.; Lin, M.J. Group Decision Making under Multiple Criteria Methods and Applications; Springer: Berlin/Heidelberg, Germany, 1987.

43. Roberts, F.S. Discrete Mathematical Models with Applications to Social, Biological, and Environmental Problems; Pearson: London, UK, 1976.

44. Steyvers, F.J.J.M.; Kooijman, A.C. Using rout and survey information to generate cognitive maps. Appl. Cogn. Psychol. 2008, 23, 223-235. [CrossRef]

45. Appleton, J. The Experience of Landscape; Wiley: London, UK, 1975.

46. Xiang, L.; Papastefanou, G.; Ng, E. Isovist indicators as a means to relieve pedestrian psycho-physiological stress in Hong Kong. Environ. Plan. B Urban. Anal. City Sci. 2020. [CrossRef]

47. Dosen, A.S.; Ostwald, M. Evidence for prospect-reuge theory: A meta-analysis of the findings of environmental preference research. City Territ. Archit. 2016, 3, 4. [CrossRef]

48. Peebles, D.; Mora, R. Effects of Geometry, Landmarks and Orientation Strategies in the "Drop-off" Orientation Task; International Conference on Spatial Information Theory: Berlin, Germany, 2007.

49. Turner, A.; Penn, A. Making isovists syntactic: Isovist integration analysis. In Proceedings of the 2 nd International Symposium on Space Syntax, Brasilia, Brazil, 29 March 1999.

50. Casanelles, E.; Longunov, E. The Nizhny Tagil Charter for the Industrial Heritage; TICCIH XII International Congress: Moscow, Russia, 2003.

51. Yang, H. A Study on Preservation, Restoration and Reuse of the Industrial Heritage in Taiwan: The Case of Taichung Creative Cultural Park. In Proceedings of the XVth International Congress of the International Committee for the Conservation of the Industrial Heritage, Taipei, Taiwan, 4-8 November 2012.

52. ICOMOS. 17th General Assembly of ICOMOS; ICOMOS Press: Paris, France, 2011.

53. $\mathrm{Xu}, \mathrm{Y}$.; Cao, Y. Cultural industrialization: A value realizing path for industrial heritage. Cross-Cultural Commun. 2012, 8, 104-107.

54. Jie, G. the Protection and Renewal of Industrial Heritage from a Landscape Architect's Perspective (A comparison between the Center of Norrköping and Xu Jiahui Park in Shanghai). Master's Thesis, European Spatial Planning and Regional Development, Blekinge Instituted of Technology, Karlskrona, Sweden, 2009.

55. Mahdavinejad, M.; Didehban, M.; Bazaz zadeh, H. contemporary architectural heritage and industrial identity in historic districts, case study: Dezful. J. Studies Iran. Islamic City 2016, 4, 41-50.

56. Yanbin, Y. Towards the Methodology for the Reuse of Industrial Heritage in China. Ph. D. Thesis, Poly Technic University of Torino, Torino, Italy, 2014.

57. Imamahwazi, M. Articles about Geographical History of Dezful; Dezful Publisher: Dezful, Iran, 2003.

58. Afsharsistani, I. Survey about the Name of Iranian Cities; Rozane publisher: Tehran, Iran, 1999.

59. Varoudis, T. DepthmapX Multi-platform Spatial Network Analysis Software. 2012. Available online: http://varoudis.github.io/depthmapX/ (accessed on 26 April 2020).

(C) 2020 by the authors. Licensee MDPI, Basel, Switzerland. This article is an open access article distributed under the terms and conditions of the Creative Commons Attribution (CC BY) license (http://creativecommons.org/licenses/by/4.0/). 